\title{
Lining bunker walls with oxygen barrier film reduces nutrient losses in corn silages
}

\author{
L. M. Lima, J. P. Dos Santos, D. R. Casagrande, C. L. S. Ávila, M. S. Lara, and T. F. Bernardes ${ }^{1}$ \\ Department of Animal Science, Federal University of Lavras, Lavras, Minas Gerais, 37200-000, Brazil
}

\begin{abstract}
The objective of this study was to evaluate 2 systems for covering corn silage in bunker silos. The first system consisted of a sheet of 45- $\mu$ m-thick oxygen barrier film (OB, polyethylene + ethylene-vinyl alcohol) placed along the length of the sidewall before filling. After filling, the excess film was pulled over the wall on top of the silage, and a sheet of polyethylene was placed on top. The second system involved using a standard sheet (ST) of $180-\mu$ m-thick polyethylene film. Eight commercial bunker silos were divided into 2 parts lengthwise so that one-half of the silo was covered with OB and the other half with a ST system. During the filling, 3 net bags with chopped corn were buried in the central part (halfway between the top and bottom of the silo) of the bunkers (CCOR) in 3 sections $10 \mathrm{~m}$ apart. After filling, 18 net bags (9 per covering system) were buried $40 \mathrm{~cm}$ below the top surface of the 3 sections. These bags were placed at 3 distances from the bunker walls $(0$ to $50 \mathrm{~cm}$, 51 to $100 \mathrm{~cm}$, and 101 to $150 \mathrm{~cm}$ ). During unloading, the bags were removed from the silos to determine the dry matter (DM) losses, fermentation end products, and nutritive value. The Milk2006 spreadsheet was used to estimate milk per tonne of DM. The model included the fixed effect of treatment (7 different locations in the bunker) and the random effect of the silo. Two contrasts were tested to compare silages in the top laterals (shoulders) with that in the CCOR (CCOR vs. $\mathrm{OB}$ and CCOR vs. ST). Three contrasts compared the corresponding distances of the silage covered by the 2 systems (OB50 vs. ST50, OB100 vs. ST100 and OB150 vs. ST150). Variables were analyzed with the PROC MIXED procedure of the SAS at the $5 \%$ level. The OB method produced well-fermented silages, which were similar to CCOR, whereas the OB system showed less lactic acid and greater $\mathrm{pH}$ and mold counts compared with CCOR. The ST method had $116.2 \mathrm{~kg}$ of milk/t less than the CCOR, as the OB system and the CCOR
\end{abstract}

Received October 9, 2016

Accepted February 23, 2017.

${ }^{1}$ Corresponding author: thiagobernardes@dzo.ufla.br were similar (1,258.3 and $1,294.0 \mathrm{~kg} / \mathrm{t}$, respectively). Regarding the distances from the walls, the effects were more pronounced from 0 to $101 \mathrm{~cm}$. The OB50 and OB100 silages had better quality and lower mold counts and DM losses than ST50 and ST100. The OB system reduced DM and nutrient losses at the shoulders in farm bunker corn silages compared with no sidewall plastic. The OB film should lap onto the crop for at least $200 \mathrm{~cm}$ so that $150 \mathrm{~cm}$ are covered outward from the wall.

Key words: aerobic deterioration, oxygen barrier film, maize silage, sidewall plastic

\section{INTRODUCTION}

The importance of corn silage to the dairy industry implies that spoilage in this feed can affect DMI (Gerlach et al., 2013) and it has fundamental implications for overall profitability of the industry (Kristensen et al., 2010). Furthermore, silage spoilage can risk the safety of operators on the farm and causes problems for consumers because of the potential transfer of microorganisms and mycotoxins from silage to milk (Cavallarin et al., 2011; Ogunade et al., 2016).

The bunker silo is widely used by livestock farms; however, this type of silo allows the corn silage to be more prone to deterioration (Bolsen et al., 1993), especially at the shoulders (Ashbell and Kashanchi, 1987; Honig, 1991; Chen and Weinberg, 2009). This can be explained by the variation of density within a bunker silo (Holmes, 2009). Silage density tends to decrease from the bottom to the peripheral layer (Muck and Huhnke, 1995). When only the upper layer is considered, density varies horizontally because the top center is denser than shoulder (D'Amours and Savoie, 2005; Borreani et al., 2008). Despite that, air can infiltrate between the wall and the cover plastic, and rain can run off the plastic and through the silage at the wall (Muck, 2011). Thus, avoiding or reducing spoilage at the shoulders of corn silages when they are stored in bunker silos becomes a key factor for commercial farms.

The management necessary to prevent aerobic deterioration in bunkers requires proper chop length, rapid 
filling, good packing, coverage with plastic, and a proper feed-out rate (Mahanna and Chase, 2003; Wilkinson and Davies, 2013). Among these alternatives, the quality of the plastic film and how well it is secured to the crop are considered keys to eliminating top spoilage (Muck, 2011). Oxygen barrier films (OB) have reduced oxygen permeability compared with standard polyethylene (PE) films (Borreani et al., 2007; Wilkinson and Fenlon, 2013). Currently, 2 types of oxygen barrier films are available on the market (Bernardes, 2016). The first one is a white-on-black sheet (130- $\mu$ m-thick), which is composed by a layer of ethylene-vinyl alcohol (EVOH) between layers of PE (known as a 1-step system). A study demonstrated that corn silage quality in the upper part was improved when this plastic film was used to cover bunker silos (Borreani and Tabacco, 2014). The second OB film is a thin sheet (45- $\mu$ m-thick $\mathrm{PE}+\mathrm{EVOH})$, which needs to be covered by a tarp or a second layer of $\mathrm{PE}$ during its application in practical conditions (2-step system). This procedure is necessary because it is not UV stabilized. Originally, the thin OB film was associated with a protective tarpaulin. However, tarpaulin cover is expensive for some producers, especially those with modest resource availability. Thus, to overcome this problem, a method that combines the thin $\mathrm{OB}$ film with a conventional PE sheet has been created for covering stack silos (Bernardes et al., 2009).

As the quality of film is not the full answer to preventing spoiled silage at the top because the film needs to be held to the forage (Muck, 2011) and the shoulders present a high risk of losses, we hypothesized that an effective way of reducing shoulder (top lateral) spoilage is to line bunker walls with the thin OB film before filling, overlap it onto the forage, and finally cover the entire silo using a PE sheet. Therefore, the aims of this study were to (1) evaluate the effect of a 2-step system on the fermentation end products, spoilage microorganisms, and nutrient losses of corn silage in dairy farm bunker silos; (2) determine how much OB film needed to be purchased for lining walls and protecting the top lateral by examining the effects of the 2-step system in different distances from the wall.

\section{MATERIALS AND METHODS}

\section{Experimental Design, Treatments, and Sampling}

Eight commercial bunker corn silages were sampled during a 2-yr period, 4 in 2014 and 4 in 2015. Bunker silos belonged to dairy farms located in the south of Minas Gerais state, which is the largest milk producer in Brazil. The width of the bunkers ranged from 4.9 to $6.5 \mathrm{~m}$, the height from 2.5 to $3.3 \mathrm{~m}$, and the length from 39 to $55 \mathrm{~m}$. The average storage period and daily feed-out rate were $134 \mathrm{~d}(98-166 \mathrm{~d})$ and $0.91 \mathrm{~m}$ $(0.68-1.13 \mathrm{~m})$, respectively. Whole-crop corn silages were harvested with both pull-type and self-propelled forage harvesters to a 12 to $15 \mathrm{~mm}$ theoretical length of cut. All corn silages were inoculated with $3.2 \times 10^{5} \mathrm{cfu}$ of Pediococcus acidilactici and Lactobacillus plantarum (Kera, Farroupilha, Brazil) per gram of fresh matter. This product is very common among dairies in this region and the company recommended the dose applied.

Two methods to seal bunker silos were evaluated, as illustrated in the Figure 1. The first method involved a sheet of $45-\mu \mathrm{m}$-thick OB film $(\mathrm{PE}+\mathrm{EVOH})$ positioned along the length of the sidewall before filling, with approximately $2 \mathrm{~m}$ of excess draped over the wall. After the silo was filled, the excess film was overlapped onto the forage, and a sheet of PE was placed on top of the OB film. The second method involved using a standard sheet $(\mathbf{S T})$ of $180-\mu \mathrm{m}$-thick PE film. This sheet protected the entire top of the silo (i.e., the OB film on

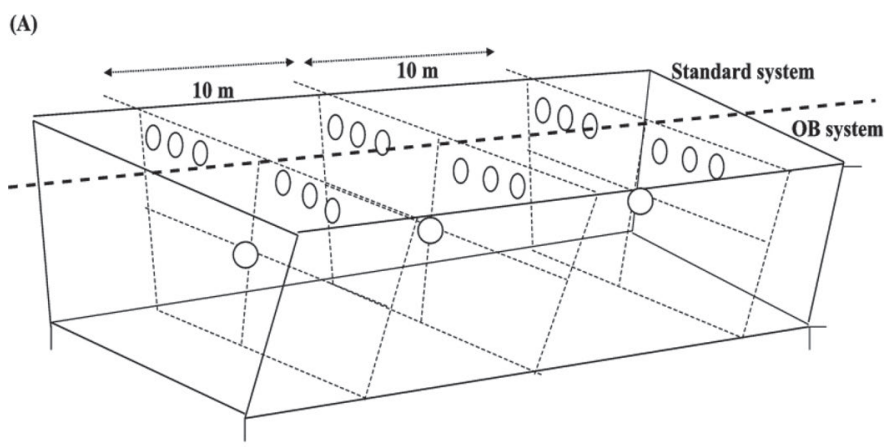

(B)

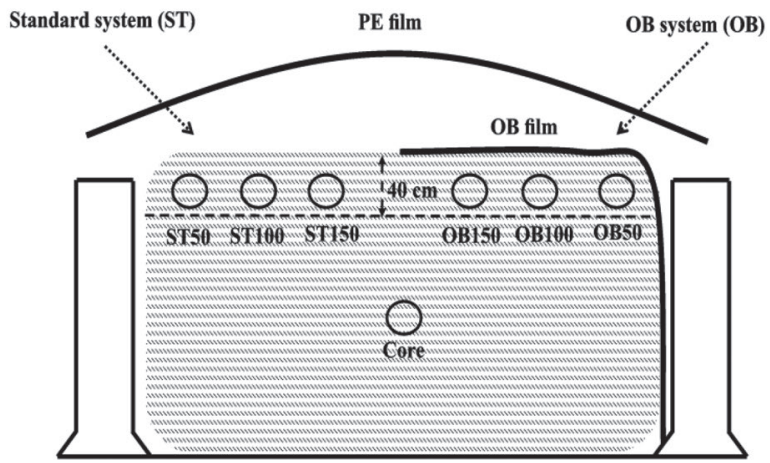

Figure 1. The 2 methods used to seal the bunker silos. (A) Bunker silos were longitudinally split into 2 parts to apply the 2 covering methods and transversally into 3 sections to bury the net bags. (B) A frontal view of the bunker showing the locations where the treatments were applied. Core $=$ central core of the silo; OB50, OB100, and OB150 and ST50, ST100, and ST150 = 0 to 50,51 to 100 , and 101 to $150 \mathrm{~cm}$ from the bunker walls for oxygen barrier film (OB) on the walls and no wall film (ST), respectively. $\mathrm{PE}=$ polyethylene. 
one side and the forage on the other). Gravel bags were placed close the walls and at the middle (lengthwise) of the silo to weigh down the plastic film.

Bunker silos were longitudinally split into 2 parts to apply the 2 covering systems. At the time of filling the silo, 3 net bags containing $5.6 \pm 0.41 \mathrm{~kg}$ each of fresh chopped corn were buried in the central part of the bunkers (CCOR) in 3 sections $10 \mathrm{~m}$ apart, and thus, the 2 ends were used as borders. As the central part of the silo is not affected or slightly affected by the negative effects of the oxygen (aerobic deterioration), CCOR represented a positive control. After filling, 18 net bags (9 per covering method) containing the same amount of chopped corn were buried $40 \mathrm{~cm}$ below the top surface (Borreani et al., 2007) of the 3 sections (one bag per location), as previously described by Ashbell and Kashanchi (1987). These polypropylene net bags were placed at the following distances from the bunker walls: 0 to $50 \mathrm{~cm}, 51$ to $100 \mathrm{~cm}$, and 101 to $150 \mathrm{~cm}$ (described as OB50, OB100, and OB150 and ST50, ST100, and ST150 for OB and ST methods, respectively). When the unloading procedure reached each section, silage density was measured by taking core samples (46 $\mathrm{mm}$ in diameter and $300 \mathrm{~mm}$ long) at the bunker face using a corer fitted to an electric drill (Muck and Holmes, 2000) at 7 positions, 6 at the top (50 $\mathrm{cm}$ from the top at 25, 75 , and $125 \mathrm{~cm}$ from the wall for both sides), and 1 sample was collected in the center (half way between the top and bottom of the silo). These positions were chosen to characterize the silage density profile in the zone where the 7 treatments were located. Afterward, the bags were removed from the silage mass and weighed to determine the DM losses. All silage of each bag was carefully homogenized to assess microbial counts, fermentation end products, and nutritive value.

\section{Sample Preparation, Analyses, and Calculations}

The pre-ensiled material and the silage were split into subsamples. One subsample was oven dried at $60^{\circ} \mathrm{C}$ for $72 \mathrm{~h}$ to determine $\mathrm{DM}$ content $\left(\mathbf{D M}_{\text {oven }}\right.$, and air equilibrated, weighed, and ground in a Cyclotec mill (Tecator, Herndon, VA) to pass a 1-mm screen. Silage DM was corrected $\left(\mathbf{D M}_{\text {corr }}\right)$ for the loss of ammonia nitrogen $\left(\mathrm{NH}_{3}-\mathrm{N}\right)$, lactic acid, VFA, and ethanol during oven drying (Canale et al., 1983). All parameters are given on a DM basis and are expressed as grams per kilogram of corrected DM.

The dried, pre-ensiled, and silage samples were analyzed for total nitrogen $(\mathrm{CP}=$ total nitrogen $\times 6.25)$ by the Kjeldahl method and ash, according to the Association of Official Analytical Chemistry (AOAC, 1990). To determine the NDF content, the samples were treated with a heat stable $\alpha$-amylase without sodium sulfite inclusion, and the results were corrected for residual ash (Mertens, 2002). Starch concentration was measured according to the method described by Hall and Mertens (2008). In vitro dry matter digestibility (IVDMD) and 48-h in vitro NDF digestibility were determined by using the DAISY ${ }^{\mathrm{II}}$ (Ankom Technology Corp., Fairport, NY) method (Holden, 1999). Rumen fluid was collected before feeding from 2 cannulated cows fed a diet that consisted of $80 \%$ corn silage and $20 \%$ concentrates. The Milk2006 spreadsheet (Shaver et al., 2006) was used to estimate net energy for lactation at $3 \times$ maintenance $\left(\mathbf{N E}_{\mathrm{L}-3 \mathrm{x}}\right)$, total digestible nutrients at $1 \times$ maintenance $\left(\mathbf{T D N}_{-1 \mathrm{x}}\right)$, and milk per tonne of DM. The book value for fat content $(3.2 \% \mathrm{DM})$ was used. The pre-ensiled material was also analyzed for water-soluble carbohydrates (WSC) by using the phenol-sulfuric acid assay in water extracts and glucose as the carbohydrate standard (Hall, 2014).

The second subsample was stored as a wet sample at $-20^{\circ} \mathrm{C}$. Wet samples were extracted with a Stomacher blender (model 400 circulator, Seward Inc., Bohemia, NY) by blending for $4 \mathrm{~min}$ with distilled water at a ratio of 9:1 (water to sample). The $\mathrm{pH}$ was measured with a pH meter (model HI 208, Splabor, São Paulo, Brazil), and an ion selective electrode (Orion Star A214 $\mathrm{pH} /$ ISE benchtop meter, Thermo Scientific, Waltham, MA) analyzed the $\mathrm{NH}_{3}-\mathrm{N}$ concentration. The fermentation end products (lactic, acetic, propionic and butyric acids, and ethanol) were analyzed by using HPLC. This apparatus (Shimadzu Corp., Tokyo, Japan) was equipped with a dual detection system that consisted of a UV detector (UV-Vis SPD-10Ai) and a refractive index detector (RID 10A). An ion exclusion column (Shim-pack SCR-101H; $7.9 \mathrm{~mm} \times 300 \mathrm{~mm}$ ) was operated at $50^{\circ} \mathrm{C}$ to separate the acids and at $30^{\circ} \mathrm{C}$ to separate the alcohols. The mobile phase consisted of a $100 \mathrm{~m} M$ perchloric acid solution $(\mathrm{pH} 2.2)$ with a flow rate of $0.6 \mathrm{~mL} \cdot \mathrm{min}^{-1}$. The acids were detected by UV absorbance $(210 \mathrm{~nm})$, and the alcohols were identified with a refractive index detector.

To obtain microbial counts, the subsamples were transferred into sterile homogenization bags before suspending in a peptone physiological salt solution and homogenizing for $4 \mathrm{~min}$ in a laboratory Stomacher blender. Subsequently, 10-fold dilutions were prepared to quantify the microbial groups. Yeasts and molds were counted by using the spread plate technique on YGC Agar (Fluka, Sigma Aldrich Química, Jurubatuba, São Paulo, Brazil). The plates were incubated at $28^{\circ} \mathrm{C}$ for $72 \mathrm{~h}$.

The DM losses were calculated as the difference between the weight of DM placed in each bag at ensiling and the DM removed at the end of storage. 
The test methods used to describe the physical properties of the plastics films were as follows: ASTM D2103-10 (ASTM, 2010a), ASTM D3985-05 (ASTM, 2010b), ASTM D5748-95 (ASTM, 2012), and ASTM D1922-15 (ASTM, 2015) for thickness, oxygen permeability, puncture resistance, and tear test, respectively.

\section{Statistical Analyses}

The counts of microorganisms were log-transformed before analysis and presented as log values. Microbial counts below the limit of detection of $10^{2} \mathrm{cfu} / \mathrm{g}$ were set at the detection limit of $\log 2.0$. Data were analyzed using the mixed procedure of SAS (SAS Institute Inc., 2004). The model included the fixed effect of treatment (7 different locations in the bunker) and the random effect of silo. The value of each parameter measured was considered the average of the bags distributed in the 3 sections and thus a total of 8 replicates (silos). The same procedure was used to analyze the density profile. Two contrasts were tested to compare silages in the top laterals with that in the CCOR (CCOR vs. $\mathrm{OB}$ and $\mathrm{CCOR}$ vs. ST). Three contrasts compared the corresponding distances of the silage covered by the 2 systems (OB50 vs. ST50, OB100 vs. ST100, and OB150 vs. ST150). Significance was declared at $P \leq 0.05$.

\section{RESULTS}

\section{Characteristics of the Plastic Films and Herbage at Ensiling}

The physical characteristics of the plastic films (mean $\pm \mathrm{SD}$ ) are displayed in Table 1 . The $\mathrm{O}_{2}$ permeability differed between the films at $23^{\circ} \mathrm{C}$ with values of 39 and $1,565 \mathrm{~cm}^{3} / \mathrm{m}^{2}$ per $24 \mathrm{~h}$ for the OB and PE, respectively. The OB film was slightly better in terms of puncture resistance and tearing resistance in the machine direction than PE film. Conversely, PE film had higher tearing resistance in cross direction compared with OB film.

The characteristics of the corn forage before ensiling are shown in Table 2. The DM and WSC concentrations of the whole-crop corn plants ranged from 35.3 to $40.0 \%$ and 6.2 to $7.5 \%$ of DM, respectively. The mean starch and NDF concentrations were 36.1 and $42.6 \%$ of DM, respectively. The numbers of yeasts and molds varied from 4.9 to 6.4 and 4.8 to $6.1 \mathrm{cfu} / \mathrm{g}$ of fresh matter, respectively.

\section{Central Core of the Silo vs. Top Laterals}

Density in bunker silos varied according to silage height. Silage in the center $\left(665.5 \pm 11.8 \mathrm{~kg} / \mathrm{m}^{3}\right)$ was denser compared with the laterals sealed by OB $(572.2$ $\left.\pm 17.3 \mathrm{~kg} / \mathrm{m}^{3} ; P=0.0134\right)$ and ST systems $(571.2 \pm$ $\left.14.4 \mathrm{~kg} / \mathrm{m}^{3} ; P=0.0097 ; \mathrm{SEM}=8.28\right)$.

The lateral of the bunkers covered by the OB method had silages with less lactic acid concentrations $(P=$ $0.010)$ and greater yeast counts $(P<0.0001)$ than CCOR silages (Table 3). All other fermentative, microbiological, and nutritional parameters (Tables 3 and 4) were similar $(P>0.05)$ between the OB and CCOR silages.

Regarding fermentation end products and microbial counts between the ST system and CCOR silages (Table 3), the ST had lower lactic acid concentrations $(P<0.0001)$ and greater $\mathrm{DM}_{\text {corr }}$, ethanol, and butyrate concentrations $(P=0.029,0.019$, and 0.042 , respectively), $\mathrm{pH}$ values $(P=0.0001)$, and yeast and mold populations $(P=0.0001$ and 0.005 , respectively). With respect to the nutritive value, ash, $\mathrm{CP}$, and NDF concentrations were greater in ST than in CCOR silages $(P=0.002,0.002$, and 0.0001 , respectively). The top lateral sealed by the ST system also had less starch $(P=0.003)$ and lower IVDMD, TDN $-1 \mathrm{x}, \mathrm{NE}_{\mathrm{L}-3 \mathrm{x}}$, and predicted milk compared with the silages in the center.

Table 1. Characteristics of the plastic films (mean \pm SD of 8 samples) used in the study

\begin{tabular}{lcc}
\hline & \multicolumn{2}{c}{ Plastic film $^{1}$} \\
\cline { 2 - 3 } Item & OB & PE \\
\hline Nominal thickness, $\mu \mathrm{m}$ & 45 & 180 \\
Measured thickness, $\mu \mathrm{m}$ & $44.1 \pm 0.81$ & $176.2 \pm 3.92$ \\
Oxygen permeability, $\mathrm{cm}^{3} / \mathrm{m}^{2}$ per $24 \mathrm{~h}$ & $39.4 \pm 1.62$ & $1,565.0 \pm 29$ \\
Puncture resistance, $\mathrm{J} / \mathrm{cm}^{3}$ & $7.5 \pm 1.34$ & $5.2 \pm 0.42$ \\
MD Elmendorf tear, ${ }^{2} \mathrm{~g}$ & $446.7 \pm 43$ & $284.1 \pm 43$ \\
$\mathrm{CD}$ Elmendorf tear, ${ }^{2} \mathrm{~g}$ & $1,104 \pm 119$ & $2,082.1 \pm 50.3$ \\
${ }^{1} \mathrm{OB}=$ oxygen barrier film composed of polyethylene and ethylene-vinyl alcohol; $\mathrm{PE}=$ standard polyethylene \\
film.
\end{tabular}



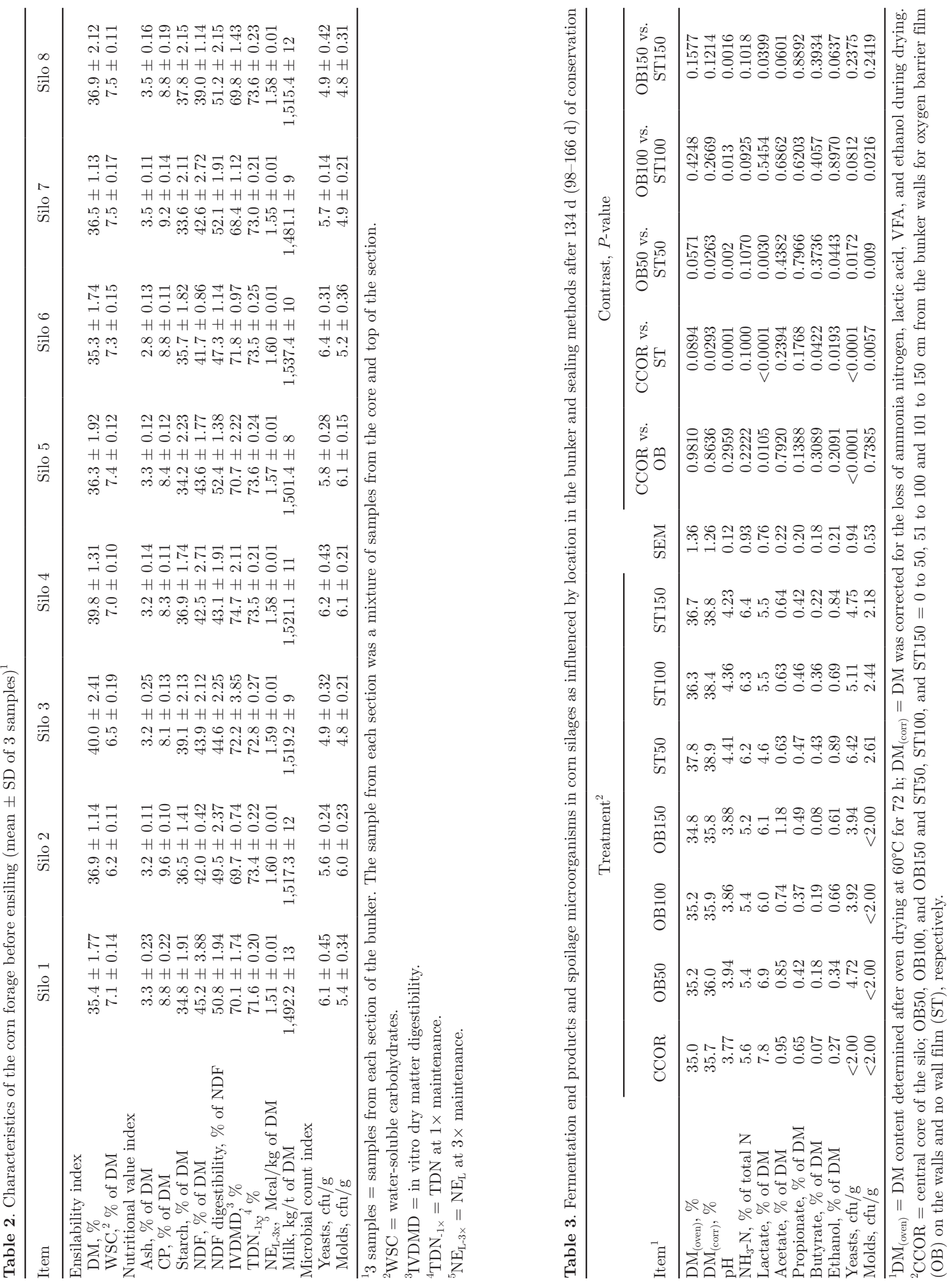


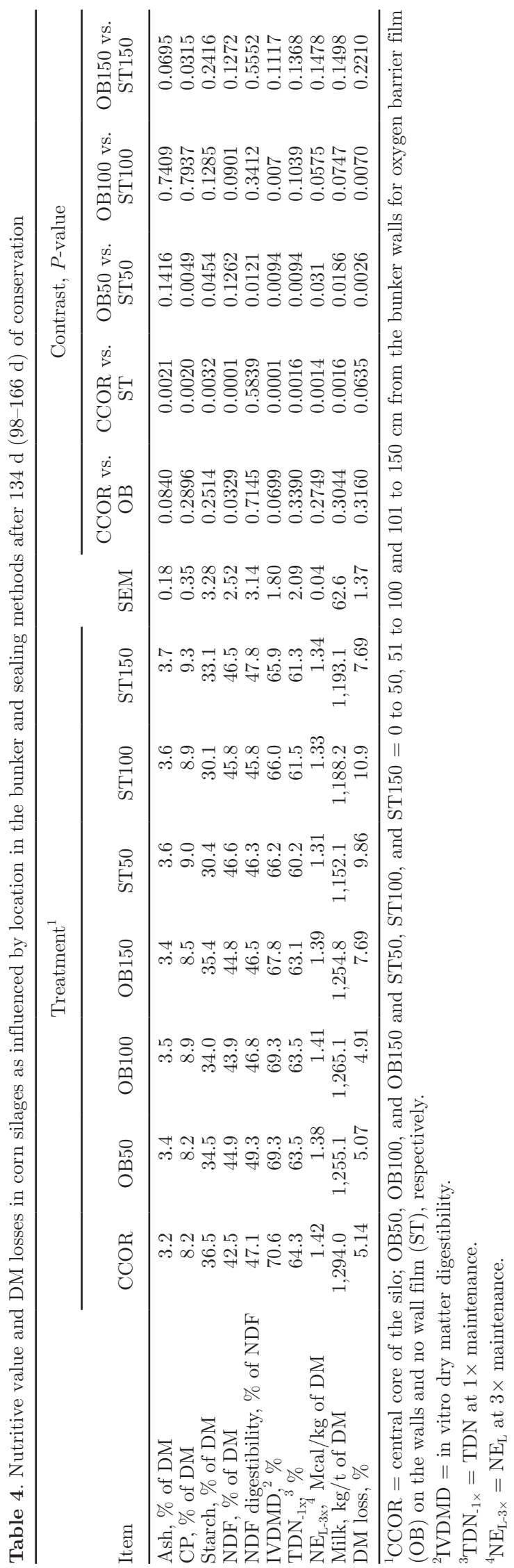

The DM losses were numerically greater in ST $(9.48 \%)$ than in CCOR silages (5.14\%); however, no differences were observed $(P=0.063)$.

\section{Corresponding Distances from the Wall in the Top Laterals}

Density was nonsignificant $(P>0.05)$ between the 2 sealing methods: the average densities were 560.7, 569.8 , and $586.0 \mathrm{~kg} / \mathrm{m}^{3}$ for the OB system and 564.9 , 560.2 , and 588.5 for the ST method for the 3 different distances from the walls of 25,75 , and $125 \mathrm{~cm}$, respectively.

Silages closest to the walls were more affected by sealing methods. Silages located at OB50 showed a better fermentation profile and lower spoilage microorganism populations than ST50 silages. The $\mathrm{pH}$ values, $\mathrm{DM}_{\text {corr }}$, lactic acid, and ethanol concentrations showed differences $(P<0.05)$ between these 2 locations. In terms of nutritive value, OB50 had lower $\mathrm{CP}(P=0.004)$ and greater starch $(P=0.045)$ concentrations than ST50. Dry matter digestibility, NDF digestibility, $\mathrm{TDN}_{-1 \mathrm{x}}$, $\mathrm{NE}_{\mathrm{L}-3 \mathrm{x}}$, and predicted milk were greater in OB50 compared with ST50.

Regarding intermediate position (OB100 vs. ST100), silages covered by $\mathrm{OB}$ showed lower $\mathrm{pH}$ and mold counts $(P=0.013$ and 0.021 , respectively). These silages also had lower DM losses $(P=0.007)$ and greater IVDMD $(P=0.045)$.

The majority of parameters were similar for the silages farthest from the walls. The $\mathrm{pH}$ values and $\mathrm{CP}$ concentrations were different between OB150 and ST150 treatments.

\section{DISCUSSION}

The effectiveness of the OB system can be seen by the fermentation profile and nutritive value of the silages, which were similar with those in the center of the silo (positive control). Silages in the core and covered by the OB system differed in 2 parameters only (lactic acid and yeast counts). It could be explained by the density variation according to silage height because CCOR was denser (lower porosity) than top laterals. In fact, yeasts are the most important microorganisms implicated in the consumption of lactic acid in the presence of oxygen in silages (Pahlow et al., 2003). Conversely, silages in the top lateral under ST system had an increase of $8 \%$ on NDF concentration and a reduction of 15 and $9 \%$ on starch concentration and predicted milk, respectively, when compared with CCOR. During aerobic deterioration process, some species, such as bacilli and molds, can grow and are able to degrade starch and hemicelluloses (Pahlow et al., 2003). Indeed, mold populations 
were greater in silages covered by the ST method. Furthermore, the ST system showed greater concentrations of ethanol and butyrate. Ethanol has a strong correlation with ethyl acetate and ethyl lactate in corn silages (Weiss et al., 2016), and these esters have an effect on air pollution (Howard et al., 2010) and DMI (Gerlach et al., 2013). Butyric acid can also reduce DMI in ruminants (Krizsan and Randby, 2007) and puts transition cows at risk for developing metabolic issues (Schultz, 1971). It demonstrates that aerobic spoilage caused by no wall plastic can affect environment, feed intake, and energy concentration. Energy is the primary nutrient contributed by corn silage to dairy cattle rations (Allen et al., 2003).

To determine how much OB plastic needed to be purchased for lining walls and protecting the top lateral, we evaluated the effects of the OB method at different distances from the wall. Silages located at OB50 showed a better fermentation profile, greater nutritive value, and lower spoilage microorganism populations than ST50. The DM losses were reduced by almost $50 \%$ with the application of the OB system at this position. In terms of losses, similar behavior was observed when OB100 and ST100 were compared (4.91 vs. 10.9\%, respectively). A study evaluated plastic films with 4 different oxygen permeabilities (ranging from 75 to $982 \mathrm{~cm}^{3} / \mathrm{m}^{2}$ per $24 \mathrm{~h}$ ) and showed a positive correlation with the DM losses (Bernardes et al., 2012). The OB100 also had lower $\mathrm{pH}$ and mold counts and greater IVDMD than ST100. Although only $\mathrm{pH}$ values showed significance between OB150 and ST150, numerically the OB150 silages had better quality (e.g., estimated milk was 5\% lower in ST150 than OB150). In practical conditions, these slight enhancements may be important for the farmers. Because silage densities were similar between covering methods at the 3 positions, the improvements in silage quality previously discussed can be attributed to OB system. Thus, we recommend that after placing the plastic film on the wall, the producer should extend it an additional $200 \mathrm{~cm}$ so that an area of $150 \mathrm{~cm}$ outward from the wall is covered.

Bunker silos have been widely used as storage facilities on dairy farms because they offer large storage capacities at a relatively low cost (Savoie and Jofriet, 2003). However, since the first studies on bunker silo management were published (Ashbell and Kashanchi, 1987; Bolsen et al., 1993), the importance of controlling top spoilage losses, especially at the top laterals, has been reported. In 1991, a German researcher in his review stated, "A problem still not fully solved is the connection of the cover to the bunker silos," referring to DM losses at the shoulders (Honig, 1991). Although he recommended lining bunker walls as a strategy to reduce losses at the shoulders, a few studies have been published on that issue. McDonell et al. (2007) measured the effects of a $\mathrm{PE} /$ polyamide sheet (the first generation of $\mathrm{OB}$ films) on the bunker wall associated with a tarp on 5 variables (DM, NDF, $\mathrm{pH}$, lactate, and butyrate) and concluded it maintained a higher corn silage quality than no wall plastic. In a review of silage management, Muck (2011) also reported the positive effects of a $\mathrm{PE} /$ polyamide sheet protected by a net on a fermentation profile. Griswold et al. (2010) evaluated bunkers silos with PE film or without sidewall plastic; however, the method they used to assess silage covering is not recommended because treatments should be compared in the same silo (Borreani et al., 2007).

Therefore, to our knowledge, this is the first research focused on reducing aerobic spoilage at the top lateral by the application of 2-step system in a large number of farm bunker silos. The technology proposed in this study explores the benefits of a new-generation OB film (Borreani and Tabacco, 2014) and in a manner that producers can apply and associate it in farm conditions. The co-extrusion between EVOH and PE produces plastic films with high oxygen impermeability. It occurs because the low polarity of $\mathrm{O}_{2}$ and $\mathrm{CO}_{2}$ exhibit only weak interactions with the high polar groups in OB film. This weak interaction combined with the presence of crystalline regions reduces the permeability rates of the gases (Stern et al., 1987) and consequently the growth of spoilage microorganisms (yeasts and molds). Besides the oxygen barrier promoted by the film, securing it close to the forage is essential (Weinberg and Ashbell, 2003). The best film cannot prevent spoilage losses if it is not secured to the crop (Muck, 2011). Lining the inside of bunker walls before filling is an alternative to guarantee the connection between the plastic and the top lateral. Thus, the OB method fulfills the 2 essential functions of a covering system (i.e., high-quality plastic film and the tight contact with the crop). Although OB film has good puncture resistance and tear strength (Table 1), it should be protected from holes that can be caused by silo filling operations. Furthermore, in this method, a protective tarpaulin can be replaced by a PE layer to cover the thin film because a tarp has to be used for multiple years to be cost effective.

Because OB films are considered new technologies and have higher prices than PE films producers are more reluctant to purchase them. However, they need to instead examine the economic benefits ( $\$ / \mathrm{t}$ ensiled) promoted by barrier films, as reported by Borreani and Tabacco (2014), to pay attention to prices. During times of economic pressure, such as those in recent years due to the high price of grain and corn forage, it is crucial that nutrients are preserved during silage storage as demonstrated by our findings when the $\mathrm{OB}$ method was used. 


\section{CONCLUSIONS}

The use of a thin OB film on the wall covered by $\mathrm{PE}$ sheet reduces DM and nutrient losses at the shoulders in farm bunker corn silages compared with no sidewall plastic. The OB film should be lapped onto the crop for at least $200 \mathrm{~cm}$ so that $150 \mathrm{~cm}$ are covered outward from the wall. This method produces silages with similar characteristics to those located in the central part of the silo because anaerobic conditions at the top are maintained due to the good properties of the plastic, and for holding it against the forage.

\section{ACKNOWLEDGMENTS}

We thank all of the dairy farmers for their patience and collaboration in this research; Silostop (London, UK) for kindly supplying the OB plastic film and partially funding the research; the National Council for Scientific and Technological Development (CNPq; Brasília, Brazil), and the Minas Gerais Research Foundation (FAPEMIG; Belo Horizonte, Brazil) for providing scholarships; and the members of NEFOR (Brazilian Forage Team) for their contributions during the field setup.

\section{REFERENCES}

Allen, M. S., J. G. Coors, and G. W. Roth. 2003. Corn silage. Pages 547-608 in Silage Science and Technology. Vol. 42. D. R. Buxton, R. E. Muck, and J. H. Harrison, ed. Am. Soc. Agron., Crop Sci. Soc. Am., and Soil Sci. Soc. Am., Madison, WI.

AOAC. 1990. Official Methods of Analysis. 15th ed. AOAC International, Arlington, VA.

Ashbell, G., and Y. Kashanchi. 1987. In silo losses from wheat ensiling in bunker silos in subtropical climate. J. Sci. Food Agric. 40:95-103.

ASTM. 2010a. ASTM Standard method ASTM D2103-10. Standard specification for polyethylene film and sheeting. American Society for Testing Materials (ASTM), Philadelphia, PA.

ASTM. 2010b. ASTM Standard method ASTM D3985-05. Standard test method for oxygen gas transmission rate through plastic film and sheeting using a colometric sensor. American Society for Testing Materials (ASTM), Philadelphia, PA.

ASTM. 2012. ASTM Standard method ASTM D5748-95. Standard test method for protrusion puncture resistance of stretch wrap film. American Society for Testing Materials (ASTM), Philadelphia, PA.

ASTM. 2015. ASTM Standard method ASTM D1922-15. Standard test method for propagation tear resistance of plastic film and thin sheeting by pendulum method. American Society for Testing Materials (ASTM), Philadelphia, PA.

Bernardes, T. F. 2016. Advances in Silage Sealing. Pages 53-62 in Advances in Silage Production and Utilization. Vol. 1. T. Da Silva and E. M. Santos, ed. InTech, Rijeka, Croatia.

Bernardes, T. F., L. G. Nussio, and R. C. Amaral. 2012. Top spoilage losses in maize silage sealed with plastic films with different permeabilities to oxygen. Grass Forage Sci. 67:34-42.

Bernardes, T. F., R. A. Reis, M. K. Miyazaki, and A. P. T. P. Roth 2009. Aerobic deterioration in corn silage covered with oxygen barrier film in stack silos. Pages 215-216 in Proc. 15th Int. Silage. Conf., Madison. U.S. Dairy Forage Research Center, USDA-Ag- ricultural Research Service and University of Wisconsin-Madison, College of Agricultural and Life Sciences.

Bolsen, K. K., J. T. Dickerson, B. E. Brent, R. N. Sonon Jr., B. S. Dalke, C. Lin, and J. E. Boyer Jr.. 1993. Rate and extent of top spoilage losses in horizontal silos. J. Dairy Sci. 76:2940-2962.

Borreani, G., T. F. Bernardes, and E. Tabacco. 2008. Aerobic deterioration influences the fermentative, microbiological and nutritional quality of maize and sorghum silages on farm in high quality milk and cheese production chains. Rev. Bras. Zootec. 37:68-77.

Borreani, G., and E. Tabacco. 2014. Improving corn silage quality in the top layer of farm bunker silos through the use of a next-generation barrier film with high impermeability to oxygen. J. Dairy Sci. 97:2415-2426.

Borreani, G., E. Tabacco, and L. Cavallarin. 2007. A new oxygen barrier film reduces aerobic deterioration in farm-scale corn silage. J. Dairy Sci. 90:4701-4706.

Canale, A., A. Ciotti, and M. E. Valente. 1983. Metodi analitici per la valutazione della qualitá di conservazione degli insilati [Analytical methods to assess silage quality]. Centro di Studio per L'alimentazione degli Animali in Produzione Zootecnica del C.N.R. and Istituto per la Meccanizzazione Agricola del C.N.R., Torino, Italy.

Cavallarin, L., E. Tabacco, S. Antoniazzi, and G. Borreani. 2011. Aflatoxin accumulation in whole crop maize silage as a result of aerobic exposure. J. Sci. Food Agric. 91:2419-2425.

Chen, Y., and Z. G. Weinberg. 2009. Changes during aerobic exposure of wheat silages. Anim. Feed Sci. Technol. 154:76-82.

D'Amours, L., and P. Savoie. 2005. Density profile of corn silage in bunker silos. Can. Biosyst. Eng. 47:2.21-2.28.

Gerlach, K., F. Roß, K. Weiß, W. Büscher, and K. H. Südekum. 2013. Changes in maize silage fermentation products during aerobic deterioration and effects on dry matter intake by goats. Agric. Food Sci. 22:168-181.

Griswold, K. E., E. McDonell, L. Kung Jr., and P. H. Craig. 2010. Effect of bunker silo sidewall plastic on fermentation, nutrient content and digestibility of corn silage. J. Dairy Sci. 93(Suppl.):622.

Hall, M. B. 2014. Selection of an empirical detection method for determination of water-soluble carbohydrates in feedstuffs for application in ruminant nutrition. Anim. Feed Sci. Technol. 198:28-37.

Hall, M. B., and D. R. Mertens. 2008. Technical Note: Effect of sample processing procedures on measurement of starch in corn silage and corn grain. J. Dairy Sci. 91:4830-4833.

Holden, L. A. 1999. Comparison of methods of in vitro dry matter digestibility for ten feeds. J. Dairy Sci. 82:1791-1794.

Holmes, B. J. 2009. Software applications for sizing silos to maximize silage quality. International Symposium on Forage Quality and Conservation, Piracicaba, Brazil. M. Zopollatto, G. B. Muraro, and L. G. Nussio, ed. Fundação de Estudos Agrários Luiz de Queiroz, Piracicaba, Brazil.

Honig, H. 1991. Reducing losses during storage and unloading of silage. Silage Conservation Towards 2000, Braunschweig, Germany G. Pahlow and H. Honig, ed. Institute of Grassland and Forage Research and Federal Research Center of Agriculture, Braunschweig-Volkenrode, Braunschweig, Germany.

Howard, C. J., A. Kumar, I. Malkina, F. Mitloehner, P. G. Green, R. G. Flocchini, and M. J. Kleeman. 2010. Reactive organic gas emissions from livestock feed contribute significantly to ozone production in central California. Environ. Sci. Technol. 44:2309-2314.

Kristensen, N. B., K. H. Sloth, O. Højberg, N. H. Spliid, C. Jensen, and R. Thøgersen. 2010. Effects of microbial inoculants on corn silage fermentation, microbial contents, aerobic stability, and milk production under field conditions. J. Dairy Sci. 93:3764-3774.

Krizsan, S. J., and A. T. Randby. 2007. The effect of fermentation quality on the voluntary intake of grass silage by growing cattle fed silage as the sole feed. J. Anim. Sci. 85:984-996.

Mahanna, B., and L. E. Chase. 2003. Practical applications and solutions to silage problems. Pages $855-895$ in Silage Science and Technology. Vol. 42. D. R. Buxton, R. E. Muck, and J. H. Harrison, ed. Am. Soc. Agron., Crop Sci. Soc. Am., and Soil Sci. Soc. Am., Madison, WI. 
McDonell, E. E., C. M. Klingerman, R. J. Schmidt, W. Hu, and L. Kung Jr. 2007. An evaluation of two methods to cover bunker silos to maintain the nutritive value of silage. J. Dairy Sci. 90(Suppl.): 975 .

Mertens, D. R. 2002. Gravimetric determination of amylase-treated neutral detergent fiber in feeds with refluxing in beakers or crucibles: collaborative study. J. AOAC Int. 85:1217-1240.

Muck, R. E. 2011. The art and science of making silage. Accessed Aug. $\quad 8, \quad 2016$. http://alfalfa.ucdavis.edu/+symposium/ proceedings/2011/11-36.pdf

Muck, R. E., and B. J. Holmes. 2000. Factors affecting bunker silo densities. Appl. Eng. Agric. 16:613-619.

Muck, R. E., and R. L. Huhnke. 1995. Oxygen infiltration from horizontal silo unloading practices. Trans. ASAE 38:23-31.

Ogunade, I. M., K. G. Arriola, Y. Jiang, J. P. Driver, C. R. Staples, and A. T. Adesogan. 2016. Effects of 3 sequestering agents on milk aflatoxin $\mathrm{M}_{1}$ concentration and the performance and immune status of dairy cows fed diets artificially contaminated with aflatoxin $B_{1}$. J. Dairy Sci. 99:6263-6273.

Pahlow, G., R. E. Muck, F. Driehuis, and S. J. W. H. Oude Elferink. 2003. Microbiology of ensiling. Pages 31-94 in Silage Science and Technology. Vol. 42. D. R. Buxton, R. E. Muck, and J. H. Harrison, ed. Am. Soc. Agron., Crop Sci. Soc. Am., and Soil Sci. Soc. Am., Madison, WI.

SAS Institute Inc. 2004. SAS/STAT 9.1 User's Guide. Version 9.1 ed. SAS Inst. Inc., Cary, NC.

Savoie, P., and J. C. Jofriet. 2003. Silage storage. Pages 405-468 in Silage Science and Technology. Vol. 42. D. R. Buxton, R. E. Muck, and J. H. Harrison, ed. Am. Soc. Agron., Crop Sci. Soc. Am., and Soil Sci. Soc. Am., Madison, WI.

Shaver, R. D., J. G. Lauer, J. G. Coors, and P. C. Hoffman. 2006. MILK2006 Corn Silage: Calculates TDN-1x, NEL-3x, Milk per ton, and Milk per acre. Milk2006corn silagev1.xls. Accessed Jan. 14, 2016. http://www.uwex.edu/ces/dairynutrition/spreadsheets. $\mathrm{cfm}$

Schultz, L. H. 1971. Management and nutritional aspects of ketosis. J. Dairy Sci. 54:962-973.

Stern, S. A., V. M. Shah, and B. J. Hardy. 1987. Structure permeability relationships in silicone polymers. J. Polym. Sci. B Polym. Phys. 25:1263-1298.

Weinberg, Z. G., and G. Ashbell. 2003. Engineering aspects of ensiling. Biochem. Eng. J. 13:181-188.

Weiss, K., B. Kroschewski, and H. Auerbach. 2016. Effects of air exposure, temperature and additives on fermentation characteristics, yeast count, aerobic stability and volatile organic compounds in corn silage. J. Dairy Sci. 99:8053-8069.

Wilkinson, J. M., and D. R. Davies. 2013. The aerobic stability of silage: Key findings and recent developments. Grass Forage Sci. 68:1-19.

Wilkinson, J. M., and J. S. Fenlon. 2013. A meta-analysis comparing standard polyethylene and oxygen barrier film in terms of losses during storage and aerobic stability of silage. Grass Forage Sci. $69: 385-392$. 